\title{
Water Supply and Treatment Design in Rural Belize: A Participatory Approach to Engineering Action Research
}

\author{
Cara Magoon \\ Senior, Civil and Environmental Engineering \\ University of Virginia \\ Charlottesville, VA 22904 \\ cmm8kb@virginia.edu \\ Additional Authors \\ Julie Evans \\ Junior, Civil and Environmental Engineering \\ University of Virginia \\ Charlottesville, VA 22904 \\ je5a@virginia.edu \\ Ariel Sayre \\ Sophomore, Civil and Environmental Engineering \\ University of Virginia \\ Charlottesville, VA 22904 \\ ats2z@virginia.edu
}

\author{
Kathryn Villars \\ Senior, Civil and Environmental Engineering \\ University of Virginia \\ Charlottesville, VA 22904 \\ kev2n@virginia.edu
}

\author{
Brian Hickey \\ Senior, College of Arts and Sciences \\ University of Virginia \\ Charlottesville, VA 22904 \\ bth2b@virginia.edu \\ Christopher Tutino \\ Senior, Biomedical Engineering \\ University of Virginia \\ Charlottesville, VA 22904 \\ cmt5b@virginia.edu
}

\author{
R. J. Swap \\ Research Associate Professor, \\ Department of Environmental Sciences \\ University of Virginia \\ Charlottesville, VA 22904 \\ rjs8g@virginia.edu
}

\begin{abstract}
As part of a long term engagement in a rural community in western Belize, students responded to community leaders' requests for an investigation of possible solutions to their water quality and supply problems. A student research team comprised of engineering and humanities students aimed to employ participatory action research methods to further understand existing challenges and develop a prototype for a water treatment and supply system. After careful analysis of local resources and constraints, the team decided that the most successful solution would combine the use of biofilters to purify the public spring water supply and improved rainwater collection to make use of the extensive storm season. An integrated prototype of these systems was built at the village government school with the purpose of serving as a model for replication in households throughout the village. In a discussion of the team's methods and reflections, this paper emphasizes the importance of finding a balance between making a design both relevant to the community and technologically successful.
\end{abstract}

Index Terms - Belize, participatory research, rural infrastructure, water treatment. 


\section{INTRODUCTION}

The UN Millennium Development Goals call for the proportion of people without sustainable access to safe drinking water to be reduced by one half by the year $2015^{\mathrm{i}}$. Unfortunately, this global challenge tempts an engineer to believe that there is a single technological fix that will address the needs of some monolith of underserved communities. However, the reality is more complex in that each region and community that currently lacks access to safe drinking water has its own unique set of resources and constraints. Hence, in recent years we have seen the emergence of a new model in which engineers are getting involved in projects at the community level to address not only the technical elements of design, but the human engineering issues that arise when technology meets culture. This shifting view of an engineer's role in development projects is reflected in the emergence of groups such as Engineers Without Borders and Engineers for a Sustainable World. These programs use a methodology that allows the design, maintenance strategy, ownership and economics of the design system to be specifically tailored to each locality over a long period of engagement ${ }^{\text {ii }}$. This paper will follow one design team's efforts to use a similar project model to develop a locally tailored water quality improvement project and contamination study in a small rural village in Belize. Both the technical design and the lessons learned in the process of human engineering through service-learning are outlined within in an effort to communicate the complexity of the struggle to make a project both relevant to the community and technologically successful.

\section{BACKGROUND}

This summer of 2009 project was not a one-time event, but rather a culmination of events over a fifteen month process of building relationships in and around the community of La Gracia, Belize. La Gracia is a small rural farming village that is largely inhabited by families of refugees from Guatemala and El Salvador. Although it is located only twenty kilometers approximate linear distance from the national capital of Belmopan as shown in Figure 1, the separation in terms of the municipal services available is much greater.

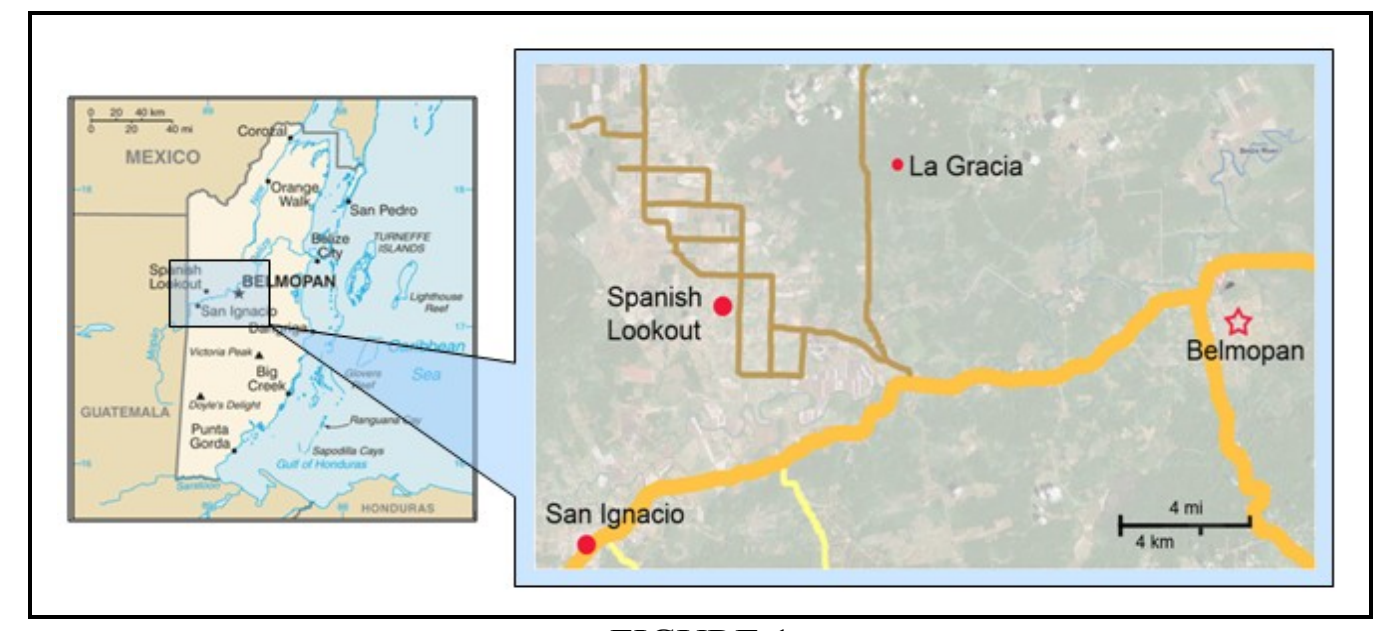

FIGURE 1

A map of Belize showing distances between La Gracia Village and the nearest cities 
In Belize, water supply is provided by the government through a privately contracted company, Belize Water Services. However, this water is available only in relatively urban areas while nearly half of the population lives in rural villagesiii. La Gracia, as a rural border community, has access to a government dug well and a gravity fed distribution system that was installed by the Social Investment Fund of Belize. The well is theoretically monitored annually for quality by a Public Health Inspector from the Belize Ministry of Health, but lab facilities are limited and transportation to these communities for testing is difficult, particularly in the rainy season $^{\text {iv }}$. Our research revealed that the distribution system had been out of service for three months of the previous summer, the well water was contaminated with pathogens and parasites, efforts to disinfect the water at the tanks with chlorine had failed, and continued assistance from outside organizations was required to move the well three times in the past twelve years to keep up with the demand for water. Therefore, despite attempts at improvements, water quality and availability continue to be a major problem for the residents of La Gracia. Through our project we sought to bring together key players from the community, government and local universities to create an engaged and collaborative group that could effectively address this important unmet need.

\section{Preparation}

This project began when the principal of the village school voiced his concerns about the water quality of the village to one of the future project team members who was participating in a service-based Alternative Spring Break (ASB) trip during the Spring of 2008. This trip to the village initiated the relationship between the community and the student team, and furthered the students' understanding of the community's expressed and observed needs concerning water. It was also an opportunity to confirm that the village well had high levels of coliform bacteria and E. coli through the culturing of water samples from the village school, the main well and the distribution tank. Being unable to foresee that the University of Belize in Belmopan would allow them to use their laboratory facilities, the students purchased and used a gel-based medium that did not require incubation to grow the colony-forming bacteria of concern in the testing plates. This gel-based plating technique led to qualitative rather than quantitative results that showed that while the water in the well and distribution tank was not free from coliform bacteria, its level of contamination was significantly lower than the water in the standpipes throughout the village, thereby leading the team to conclude that the water distribution network must be contaminated. Therefore the decision was made to focus on decentralized or household treatment rather than a centralized treatment system that might treat the water at the source but would ultimately expose the water to recontamination through distribution.

In the Fall of 2008 the project team expanded to three students, all of whom were studying civil and environmental engineering. As part of a recently developed course at the University of Virginia called "Engineering in Community Settings," they began designing a project to further study and address water quality issues in La Gracia. Project design continued through the late fall into early spring of 2009, during which the team developed a number of proposals to programs that supported undergraduate service learning and community engagement activities. These programs required letters of community support, which led the team to pursue further communication with the village school principal and other members of the community. Initial discussions involved the principal circulating a message among the residents of La Gracia, a 
letter of support with signatures from interested community members, and introductory conversation with the village chairman.

After receiving funding, two team members went on a site assessment visit in March of 2009 to talk to community members individually about project ideas. In these conversations, the students introduced themselves, explained how the principal had consulted them about water quality and access, listened to people's comments on local water quality, and discussed ideas for what could be accomplished during the summer project considering their limitations as students. In addition, the team members surveyed the topography of the village as well as the location of water supply points and the water distribution system using GPS. It was on this trip, during discussions with community members, that the decision was made to use the school as a site to develop a locally informed water treatment prototype. The prototype would be built in a central location as part of a series of community workshops in which residents could learn how to construct similar systems for installation in their own homes.

To increase the team's effectiveness, we chose to expand to a total of seven student team members having interdisciplinary backgrounds with one of the students coming from Galen University in Belize. This larger team was deemed necessary as the scope of the project continued to expand as illustrated in Figure 2 below. Specifically, the student partner from Galen was an anthropologist and acted as an important cultural liaison, especially as we attempted to involve the community as much as possible in our design approach.

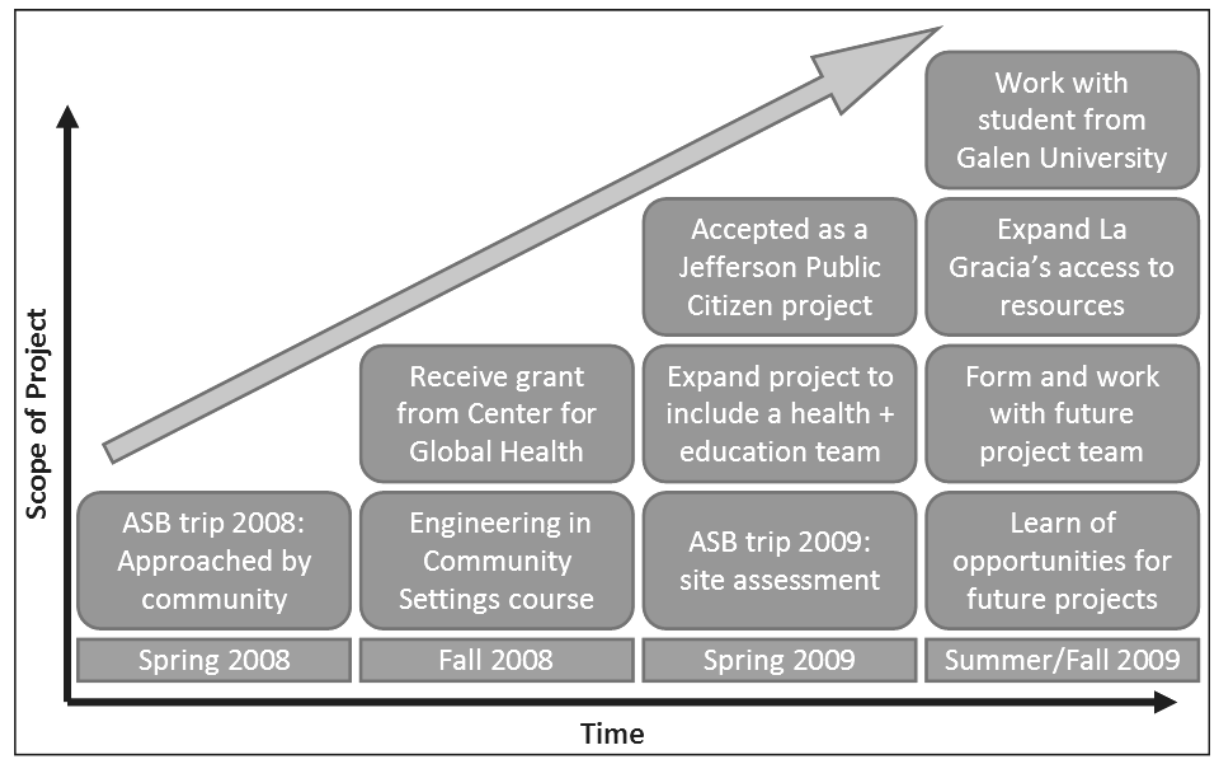

FIGURE 2

GRAPHICAL REPRESENTATION OF THE EXPANDING SCOPE OF THE PROJECT OVER TIME

In preparation for the in-country portion of the project, the team spent time researching and designing our project methodology. The goals of this study were to (1) investigate the origins of contamination and possible mitigation techniques, (2) identify all drinking water sources and methods of treatment, (3) design an appropriate treatment method for the village to be constructed as a prototype at the school, (4) raise awareness and understanding of the connection between water, hygiene, and health, (5) identify potential community leaders who are interested 
in these issues and empower them as true partners in the project, and (6) effectively communicate all gained knowledge back to the stakeholders in the community

The team was structured into two subgroups: one with the three civil engineering students focused on addressing the first three goals and another focusing on goal four. Both teams worked together in addressing the last two goals. This paper will focus largely on the work of the first subgroup, but in reality the work of the two groups cannot be separated as the findings of community health and perceptions of water quality certainly influenced the design of the treatment system. Our areas of research included water treatment options, water source protection techniques, methods for participatory community-based research, methods for responsible service-learning, health education program components, and sources and pathways for disease. Our goal before travelling to Belize was to compile resources and knowledge on a wide range of treatment techniques so that we would not be limited to a single solution that might later prove to be inappropriate for the community. Instead we wanted to utilize an iterative design process wherein our design ideas could be constantly reviewed and reevaluated not only by the team and our advisors, but by community members and with consideration of the on-site observations made by the team.

\section{Participatory Solution Design Process}

Although not traditionally considered part of the engineering design process, when working with communities, especially in international settings, it is critical to have a broad sense of engagement with community partners. The community cannot be seen as a passive entity that will readily make use of whatever design it is given. Rather, the community should be seen as a true client whose reciprocal relationship with the design team must influence the design to make it relevant to their needs. Furthermore, the design team must have a constant awareness of the way local culture influences language, literacy, gender roles, and financial constraints as each researcher interacts with stakeholders to develop and communicate the project design. From the moment our community client sought out assistance from the first student researcher and throughout the solution design process, every effort was made to treat the community as a participatory client.

The design process began with an on-the-ground site assessment that familiarized the project team with both the locally available resources and the complexity of the needs of the community client. We spent five days visiting various government offices and NGOs in the three major cities of Belize: Belize City, Belmopan, and San Ignacio. Through these visits we were able to learn more about the political and economic contexts that influence the supply of water to rural communities, acquire the plans of the engineer who designed the recent modifications to the La Gracia water distribution system, and learn from the Public Health Inspector for La Gracia that the village's water quality had not been tested in four years. By visiting many of these groups we were able to gain a more complete understanding of the existing situation and identify ways to foster communication and renewed interest among these stakeholders. These visits also included a trip to Galen University where we met our seventh team member who would aid in both the design of an appropriate solution and cultural fluency in communicating with residents.

Next, the team arrived in La Gracia Village to begin on-site observations, interviews and sampling. Work began by interviewing at least one member of each household in the community, allowing us to hear a wide array of ideas, opinions, and concerns of people in the village. During these interviews we learned that many people were aware of the poor well water quality and 
were already using alternative sources such as rainwater or private hand-dug wells. We often engaged in more extensive interviews with those that were more proactive in handling the problems of poor water quality and supply so that we could incorporate their solutions and methods in our technical and educational designs. In this way we could circulate both foreign and local knowledge throughout the village and involve community members as true partners in the solution design process. After inspecting and testing some of these improvised household rainwater systems we found that the rainwater samples were generally much cleaner than the well water samples. However, at specific households, problems in the method of collection resulted in poor quality of their rainwater. From these interactions it began to appear as if rainwater collection may be an ideal treatment option for La Gracia since it was already a familiar practice that could be improved and made consistently safe with a small amount of education.

\section{Initial Design: Evaluation of Constraints and Opportunities}

A wide range of "appropriate" technologies exist for use in rural community settings, yet rather than choosing one system early in the project and making it work in the specific context of La Gracia, we decided to wait until we had a more complete understanding of the needs, constraints, and resources of the community. To begin the design process we set out to determine our technical design options and constraints via a survey of locally available materials, transportation options, and technical expertise. It was not until this materials assessment was complete and the concerns and expectations of the community were heard and understood that the design team was able to fully evaluate the available options for treatment systems.

To further understand design options and constraints, the team continued local networking, conducted targeted interviews, and a created village message board. The principal and the staff at the supply stores in Spanish Lookout aided us in expanding our local network by referring us to a local carpenter who had worked on other school improvement projects and a solar panel installation specialist. These local experts worked with us in designing and installing of the water tank support structures and the solar-powered pump. Initial interviews with government agencies who work with rural development and village governance led us to additional interviews with the village water board members in La Gracia and the lead civil engineer who had worked on the central well and distribution system in La Gracia. These local experts influenced the initial design by encouraging the creation of a prototype at the school, sharing knowledge of the local soil properties and currently used methods for gaining access to safe water, and sharing ideas and concerns about the use of chemical disinfectants for water treatment. Furthermore, the team located a message board at each of the two village stores where we posted our current and planned activities and encouraged questions or comments to be written anonymously on the supplied writing pad. These questions or comments were submitted in a re-sealable envelope and gathered by the team each day. For every comment or question, the team deliberated on a response and posted it on the message board. In this way, we were able to address concerns and incorporate ideas from those that we had not had the chance to interview or who had not communicated everything they had to say in the interviews. This process continued throughout our stay in La Gracia.

Additional design considerations specific to the school prototype came from discussions with the principal and observations of water use by the children at the school. We had several meetings with the school's principal to discuss the most technically feasible design options: solar 
distillation, biofilters, rainwater collection, and chemical disinfection. Since the prototype was to be constructed for the school, he was able to provide meaningful feedback on the relative usability and safety of the design. From his feedback, we began to realize the advantage of constructing the system at the school where a central figure was authorized to make decisions and provide maintenance and security to the system. Furthermore, he was able to answer our questions about the school's daily water demand and provide insight on how water use changes during the year. These meetings also served as a forum for our team and the principal to clearly communicate mutual expectations of the project and for us to provide updates on our work.

The most technologically feasible design options were determined in part by material availability. As students from the United States where one is always within a short drive of a one-stop home construction warehouse, it is difficult to realize both the extent to which material availability can limit your design and the time and effort that is required simply to find, purchase and transport the materials that are needed. In order to understand the material constraints of the project, we conducted a survey of stores selling construction supplies in the area and asked for inventory lists and pricing for relevant materials such as piping and water storage containers. Available storage tank sizes, piping material, construction materials, and associated costs caused us to favor certain design options and eliminate others, such as solar distillation. Beyond limited inventory, we faced the difficulty of transporting materials to La Gracia from supply stores, which were a thirty minute drive down an occasionally impassible unpaved road. Therefore, we realized the need to allocate far more time and funds than we had anticipated to the acquisition and transport of materials in our projected design-build timeline and budget.

Ultimately we decided to (1) increase the school's capacity to collect and store improved rainwater and (2) construct biofilters to improve the quality of the water they could access from the village well during the dry season. In addition to these two goals for water treatment at the school, we would continue to study the relationship between water-related behaviors and human health so that we could create an effective locally-tailored education program to be implemented in the last days of our stay in the village.

\section{Initial Design: Calculations and Measurements}

The goal of our contamination research was to understand where different sources of contamination were entering the village water system so that we could educate residents about ways to improve water source quality. Originally, the team had planned to use tracer dye analysis, a method they had found in their research, to study surface and groundwater flow through identified potential contamination sources. However, we ultimately decided that introducing dye or chemical tracers into drinking water sources would be culturally unacceptable and create unnecessary risk. Instead, the team used more qualitative survey techniques that looked at topography, bacteria counts from water samples, and relative locations of water sources and likely contamination sites. During a site visit three months before the project implementation, two team members had collected GPS data with which to create a topographic map of the village in order to study gravitational water flow. However, differences between mapping coordinates used in Belize and the U.S created unexpected difficulties and the team was not able to generate a map. In future efforts at such research it would be useful to generate more definitive information on the sources and routes of contamination, which could be achieved with access to the necessary equipment and the assistance of a professional engineer, professor, or graduate student with experience in such research. 
The rainwater collection design aimed to increase the storage capacity of the school and improve the quality of the collected water though the use of a first flush system that prevented contamination from entering the stored water supply. A first-flush system collects the first few millimeters of rainfall from each storm event and diverts it from the rainwater collection tank as this water will contain the majority of the dirt built up on the collection surface. Our particular system, as pictured in Figure 3, consisted of a 4" PVC pipe set into end of the gutter that contained a floating ball that would plug the top of the pipe as it filled.

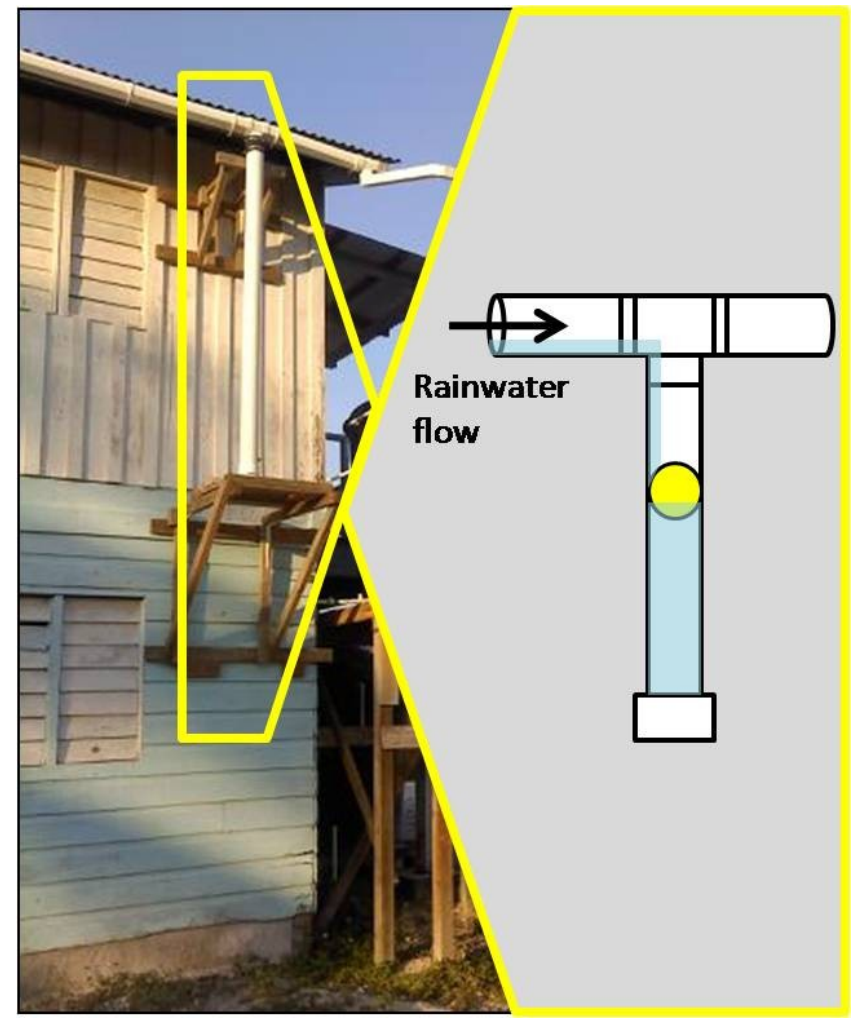

FIGURE 3

FiRST FLUSH SYSTEM AS CONSTRUCTED (LEFT) WITH SCHEMATIC DIAGRAM DEMONSTRATING SHUT-OFF MECHANISM (RIGHT)

This function would allow the rest of the rainwater, which had only passed over a now clean roof surface and was therefore of higher quality, to pass into the storage system. The volume of water that the first flush system must collect was determined using design guides that recommended diversion of 1 gallon per 100 square feet of collection surface ${ }^{\mathrm{v}}$ and calculations (5) and (6) in Table 1 below. When considering volume needed for storage capacity our inputs included the size of the roof collection surface, average annual rainfall, length of the dry and rainy seasons, and the estimated drinking water demand of the school. These parameters were used in the equations shown in Table 1 to determine the amount of surplus rainwater that could be stored during the rainy season to last through the dry season without becoming stagnant. Although La Gracia receives a large amount of annual rainfall, the dry season may last up to five months without any rain event for the two most severely dry months of February and March ${ }^{\text {vi }}$. The team decided on a total storage volume of 1,800 gallons in the form of an elevated 400 gallon collection tank flowing into a second 400 gallon distribution tank with a 1000 gallon 
overflow tank that would be filled in the rainy season and slowly drawn down with use in the dry season. This storage capacity is 260 gallons less than what our calculations estimated, but we did not want to risk storing water for so long that it might become stagnant, and further we had to work within cost and availability constraints for the tanks. The decision was made to elevate the first collection tank so that water could be gravity fed through the filters and into the distribution tank. Since the 1000 gallon excess storage tank would weigh more than four tons when full, it was infeasible to elevate it in a structurally sound manner with the materials available. Therefore the team designed for a pump to lift water from the overflow storage tank to the collection tank for gradual gravitational flow through the treatment system. Since the principal would be the operator of the constructed system, the team consulted him as to his thoughts on constructing a manual pump versus purchasing a small water pump that could be powered off of the school's solar panel. The principal preferred to operate an electric pump, which requires minimal maintenance and, if needed, could be serviced affordably by a technician at the nearby hardware store in Spanish Lookout. The team supported this decision since they had no prior experience constructing pumps and, while there was no precedent for use of manual pumps in the community, an electric pump was currently in use at the village well. Furthermore we were not confident that the capital investment and maintenance costs would be significantly reduced.

TABLE I

RAINWATER DEMAND, STORAGE, AND FIRST FLUSH CALCULATIONS PRESENTED AS FORMAL EQUATIONS AND FIELD CALCULATIONS

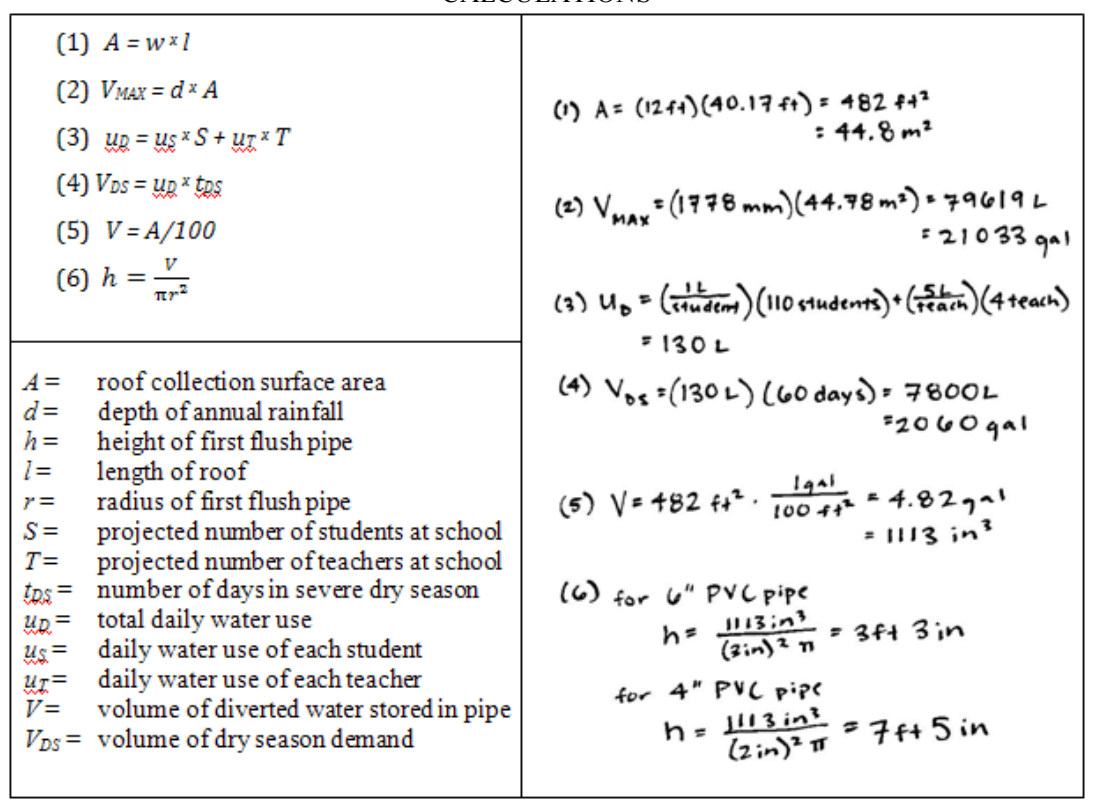

Designing the biofilter treatment system proved to be difficult with the resources available. A biofilter consists of a thick layer of sand, which serves as a physical filter, on top of which a thin biological layer of microbes will form to feed on any organic contaminants in the water. The purpose of this biolayer is to degrade any pathogens or harmful chemicals that would not be filtered by the sand and its growth requires a constant flow of water over the filters. Previous to our travel to Belize, one team member worked with another team in constructing a biofilter prototype, but the construction process proved to be an over simplified exercise that did not 
incorporate essential methods necessary for creating a successful filter. Therefore, despite attempts at a prototype in the U.S., we relied mainly on in-country design and improvisation to create the biofilters with local materials and the equipment available to us in Belize. To size the filters, the design team calculated the flow rate necessary to satisfy the school's daily water demand. Once the desired flow rate is determined, it can be achieved through altering the surface area and density and thickness of filter medium ${ }^{\text {vii }}$. However, there was only one option for an appropriately sized watertight container for the filter tank, so we did not have the option of changing the sand surface area. Additionally, the quarry where we sourced the sand and gravel for the filters did not conduct sieve size analysis for their aggregate and we did not have the necessary equipment to do so. This lack of information made it impossible to accurately calculate the necessary gradation of the aggregates and the necessary thickness required for the sand layer to generate the desired flow. Ultimately we aimed to scale up the generically recommended thicknesses as per the design handbook we were using in the field ${ }^{\text {viii. This }}$ required estimating average aggregate sizes and choosing the best options from the available materials. The biofilters were designed as fifty-five gallon drums filled with a tall layer of fine sand, followed by coarse sand and gravel.

Before beginning construction of the designed system we rendered a detailed design sketch, included here as Figure 4, and sent it to our technical advisor, a civil engineering professor at the University of Virginia for his review. 


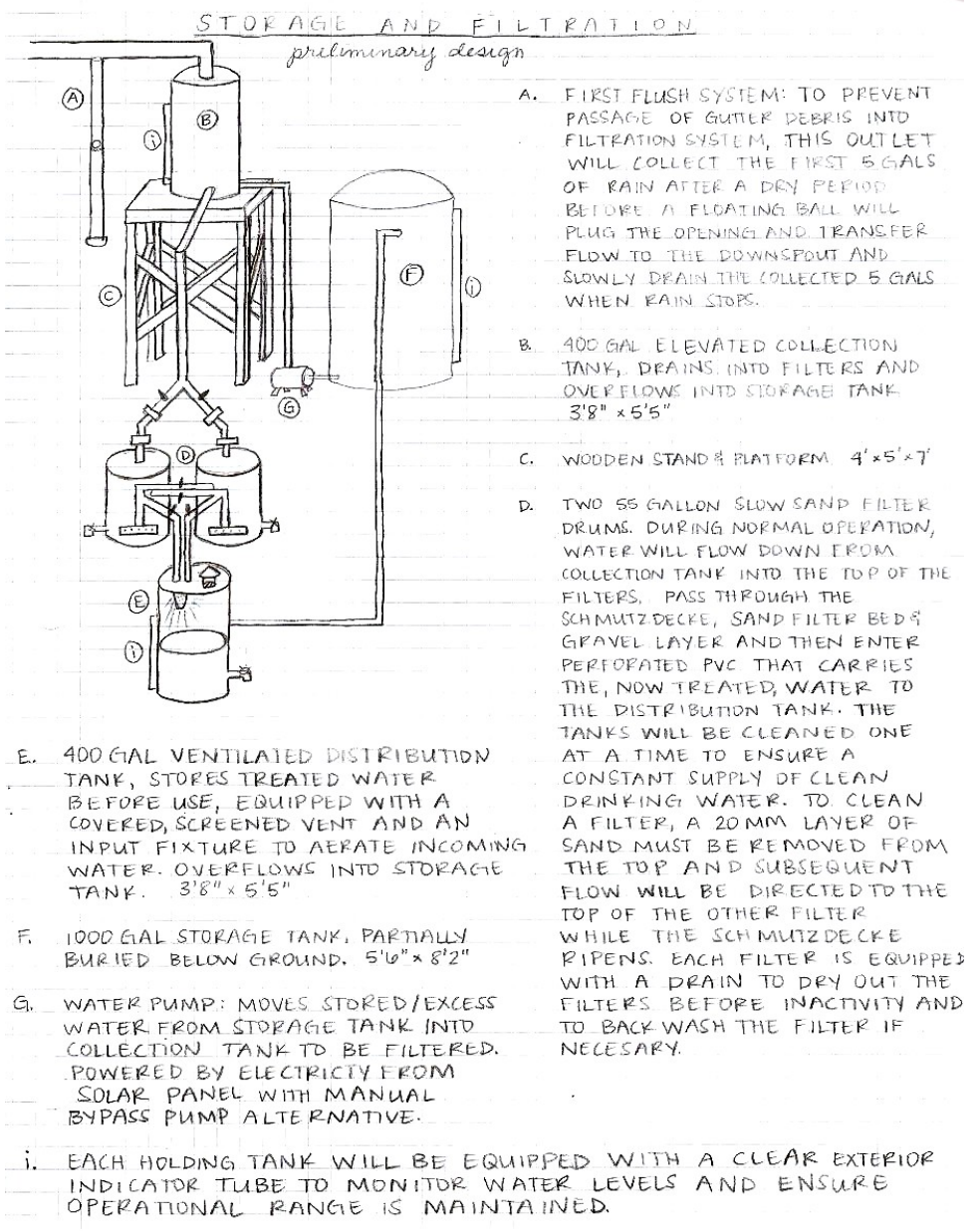

FIGURE 4

THE PRELIMINARY DESIGN AS DEVELOPED IN-COUNTRY AT TIME CONSTRUCTION BEGAN, SHOWING THE FIRST FLUSH SYSTEM, ELEVATED COLLECTION TANK, BIOFILTERS, DISTRIBUTION TANK AND BACKUP STORAGE WITH PUMP

\section{Improvising on the ground: lessons learned through construction}

After completion of the preliminary design we started constructing the system in parts, obtaining the necessary materials gradually and continually incorporating input from advisors and our own observations of the site. In this manner, we made changes to our preliminary design as necessary based on resource availability, technical requirements for proper functioning of the system, and human factors involved. The final constructed system included several changes and additions mainly to the filtration, distribution, and maintenance components as illustrated in Figure 5. 


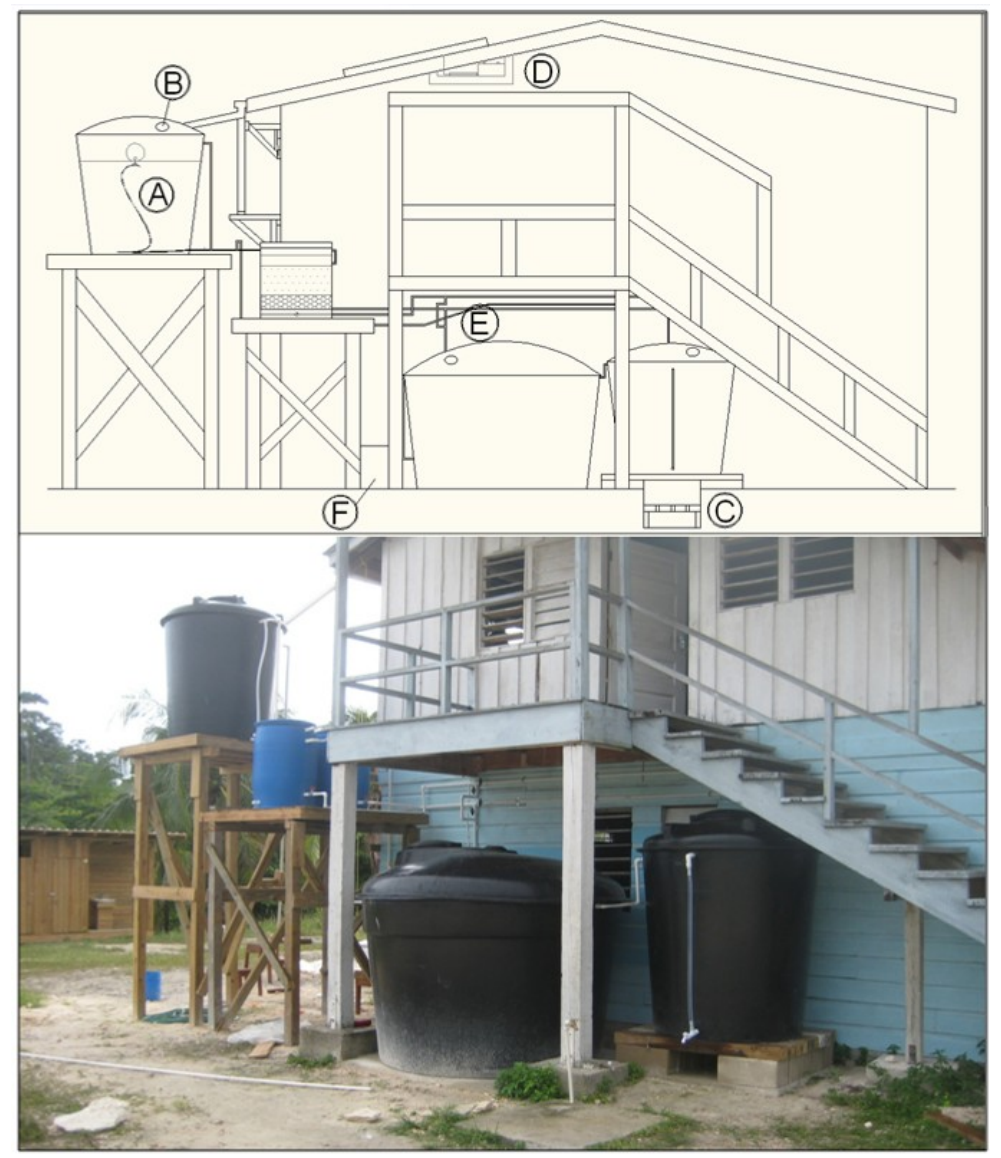

FIGURE 5

Picture of constructed system (bottom) along with a schematic (top) which includes: A) constant FLOW DEVICE: A SEALED JUG FLOATS ON THE WATER SURFACE AND SUSPENDS THE INLET OF A FLEXIBLE TUBE THAT DESCENDS WITH THE WATER LEVEL SO THE WATER PRESSURE AND OUTFLOW FROM THE TANK REMAIN CONSTANT. B) VENT: A SCREENED 4" DIAMETER HOLE IN THE TOP OF THE TANK FOR AIR CIRCULATION C) DRAIN: A PLATFORM TO SEAT A 5-GAL BUCKET WHILE LETTING WATER PASS THROUGH WAS PLACED IN THE BOTTOM OF A hole dug below the tank outlet. D) SOlar PoWer system: 120w solar Panel, Charger, 2 batteries, AND WIRING RUNNING TO THE PUMP E) BYPASS AND FILTER MAINTENANCE PIPING: VALVES IN THE PIPE NETWORK DIRECT FLOW FROM THE OPERATIONAL FILTER TO THE DISTRIBUTION TANK AND FLOW FROM THE OTHER FILTER TO THE OVERFLOW TANK DURING CLEANING. F) PUMP: 1" ELECTRIC WATER PUMP UNDER A PLASTiC COVER

There were not significant changes to the components of the rainwater collection system because of the simplicity of the design no local findings of inexpensive design innovations, and our sufficient preparatory research and instruction. The measurements required only simple, readily available tools and most of the system design and calculations only required rudimentary engineering. However, challenges remained in creating a successful aeration system for stored rainwater, and the team faced several challenges in building the complete system so that it could also provide purified groundwater. These challenges and resulting changes to the preliminary design are presented below in regards to three central factors: transportation availability, the technological feasibility of the system, and the relevance of the system to the users.

In order to buy materials, the team had to arrange rides to town with the school principal or town chairman according to their availability, as they were the only people regularly going to 
town and taxis were not willing to travel the road due to its poor condition. Other community members did travel into town occasionally, but could not accommodate the size of the team and materials. This meant we often had to wait a day or more to buy materials. In order to maintain the rate of work that would allow us to finish the system in time for testing, we often had to improvise with our on-site materials. This often led to changes in our design, from rearranging piping, to changing our elevations based on what materials we had for creating the stands for the tanks. These improvised design changes were possible because of the engineering intuition that we had developed in school. We evaluated design changes based on knowledge of fluid dynamics when we were working with the piping system and structural mechanics when working with the support structures. We realized after construction of the system that a more advanced knowledge of microbiology and aquatic chemistry would have allowed us to improvise more effectively with construction of the biofilters using local materials and equipment. However, our engineering experience was developed enough that we were able to mitigate any risks associated with our inexperience in chemistry and biology by using, for example, simple fluid mechanics to design a bypass system for the filters in case of malfunction.

The most difficult part of the design involved constructing the components of the system that would filter groundwater, allow for maintenance of the system, and manage water quality during storage. Though we did not realize it immediately, we lacked sufficient resources or knowledge of the particular type of biofilters we were using to easily construct a successful system on the first attempt. Our gathered resources lacked a description of how to maintain or analyze healthy growth of the necessary biolayer. Thinking that we may need a more steady supply of water and organic nutrient for the microbes, we added in the constant flow device shown in Figure 5. Also, our sources did not discuss mechanisms for maintaining water filtration during the cleaning of the filter, which was particularly important since it would take at least two days to re-grow the biolayer after cleaning even if we kept it wet and did not harm the deeper growing microbes ${ }^{\mathrm{ix}}$. Because of our lack of references for this aspect of the system, our preliminary design was not ideal and required us to redesign the piping as illustrated in Figure 5 in order for it to function properly. Furthermore, we did not receive feedback from our technical advisor on our initial design until we had already purchased materials and begun construction. After receiving his feedback, we added a piping network to bypass the filters when only rainwater was being collected since it would be safe to drink after passing the first-flush. Lastly, we did not have the instruments to test for the necessary oxygen levels in the water nor did our resources outline methods of aeration in storage tanks, but we realized that aeration was necessary to prevent the water from becoming stagnant. We could not find appropriate aeration devices in the area, so we improvised by engineering a miniature v-notch weir in the inlet pipe to the distribution tank so that water would spring out and mix with the air before falling into the tank. Additional aeration was provided by venting the tanks, as described in Figure 5, and by the presence of the pump, which can circulate water through the system as needed. Again, we used principles from fluid mechanics and water resources classes to mitigate risks associated with our lack of knowledge in aquatic chemistry and microbiology. All of these challenges made the solution design process less efficient, taking away from the time we had for testing, monitoring, and fine-tuning of the system. The quality of our changes could have been improved by more preparation and active technical advising, but what we accomplished worked to create a more technologically successful system.

Additional necessary changes to the preliminary design related to the needs of the users rather than the technical requirements of the system. These included considerations of safety, 
accessibility, and existing local practice. After the principal commented that the children might try to climb the elevation platforms for the water tanks, we redesigned them with input from a local carpenter who was aiding us in construction of the tallest stand. We took out the second diagonal support from each side of the structure to make the stands less appealing to climb. In addition to this measure we also talked to the school principal about educating his students regarding the danger of climbing and put up caution tape as a temporary precaution. Furthermore, in response to his additional concerns we arranged the filters, tanks, and piping to allow the principal proper space to access system components during maintenance and operation of the system. In response to our observations of another user, the school children, we rearranged the elevations and dug out enough space for the standard bucket to fit under the distribution tap, where the students would fill them in the mornings. Additionally, we dug further below the tap and installed a drain as shown in Figure 5 that would prevent the area below the tap from filling with water and eroding, making it difficult to fill buckets. The flexibility of our initial design proved useful in allowing incorporation of user input to make the end product relevant to the community it would serve.

Lastly, after finding that the rainwater barrels we intended to use for the biofilters were sold out at local supply stores due to high demand in the rainy season, we modified our design of the biofilters to be contained in a barrel type used commonly throughout the village for water storage. These barrels were used pesticide containers, which we scrubbed with soap and water and rinsed thoroughly before filling with the biofilter materials. At the time, we did not know if our cleaning methods were sufficient to rid the barrels of pesticide residuals, although we assumed that we were minimizing the chances for harmful effects by thorough scrubbing, rinsing, and allowing time for drying. Our installation of a manual bypass of the filters again served to mitigate risk in this specific situation by allowing for the filters to be bypassed if the barrels were later determined a risk, either locally or through our own further research. In retrospect, we should have used the drums to build a prototype of the filter system and offer workshops on using similar sized barrels for filter construction if the prototypes were successful. Although these barrels are readily available and it is common local practice to use them drinking water storage, the team should have employed more of a balance in our methods between a technical solution and one that was locally relevant.

Throughout the design and construction, we attempted to build a successful and sustainable water treatment system using the knowledge and experience we had gained in our studies and related extracurricular activities. Under our monitoring, the filters effectively filtered the water for a total of eleven days, but on the day before our return to the United States we observed sudden growth in coliform bacteria and an increase in turbidity likely due to problems with the gradation of the sand layers. Fortunately, our design approach maximized flexibility of the design by creating a system that could be multifunctional and adapted by the users according to their needs. The bypass that we had designed into the system allowed the water to be routed around the filters, which allowed for alternative use of the system as a means of improved rainwater collection and distribution even if it would not effectively treat groundwater for drinking. This inclusion of a bypass was an instance where our training in ethics of international service-learning guided us to make decisions that minimized risk. However, while avoiding technology can minimize risk, another sort of risk minimization is possible through proper oversight and technical advising that allows for construction of fully functional technological systems rooted in experience and expertise. This engaged technical advising could come from 
professors, graduate students, or practitioners from in-country or home institutions of higher learning.

Unfortunately, when working in-country, access to technical resources such as laboratories and communication with a technical advisor is limited. Hence we found technical problems with our design during construction and testing that had to be re-designed or, in the case of the filters, bypassed. Our designs and re-designs were not as technologically successful as desired, which was caused in part by a decision to accept local constraints in the case of the filters. Therefore finding a more equal balance between relevance to the client and technical rigor is essential to a successful project. This balance could be achieved by developing technical plans prior to arrival but leaving them very flexible as input is received on community need and local constraints are understood. Secondly, the timeframe of the site assessment versus the actual project could be reversed. A long site assessment that includes all the community interviews, local materials assessment, and survey of in-country resources could then be followed by a rigorous technical design process while back at school with access to technical software and advisors. This would culminate in a shorter construction trip to complete the project and ensure transfer of ownership to community partner. Third, a technical advisor could work alongside the students throughout the entire design and construction process.

\section{Transferring Ownership}

After building the treatment system, concluding the analysis of contamination sources, and gauging people's perceptions of the relationship between water and health, we hosted a health fair at the school to share our recommendations and results. At the fair, part of the team focused on hygienic recommendations such as keeping water storage containers covered, keeping hands out of the water buckets when distributing water, and washing hands. They also tried to overcome the common aversion to chlorine by holding a "taste test" between a flavored drink made with non-chlorinated water and one made with chlorinated water. This was to encourage point-of-use chlorination and was accompanied with instructions and free chlorination tablets. Previous to the fair, this part of the team had shared their findings on perceptions of water and health through a unique conversation based on photographs that volunteers had taken regarding water and health in their daily lives. Some of these pictures were displayed at the health fair and provided a focal point for discussion, along with the school treatment system.

The other part of the team focused on providing recommendations for controlling water contamination, building or improving rainwater collection systems, and purifying drinking water at home. We made illustrated posters that described each of these topics in detail and presented them to the group (Figure 6) before opening up the room for questions and allowing people to walk around and take a closer look. Our local student partner took part in creation of the posters and was present at the presentations to clear up any misunderstandings in translation. 


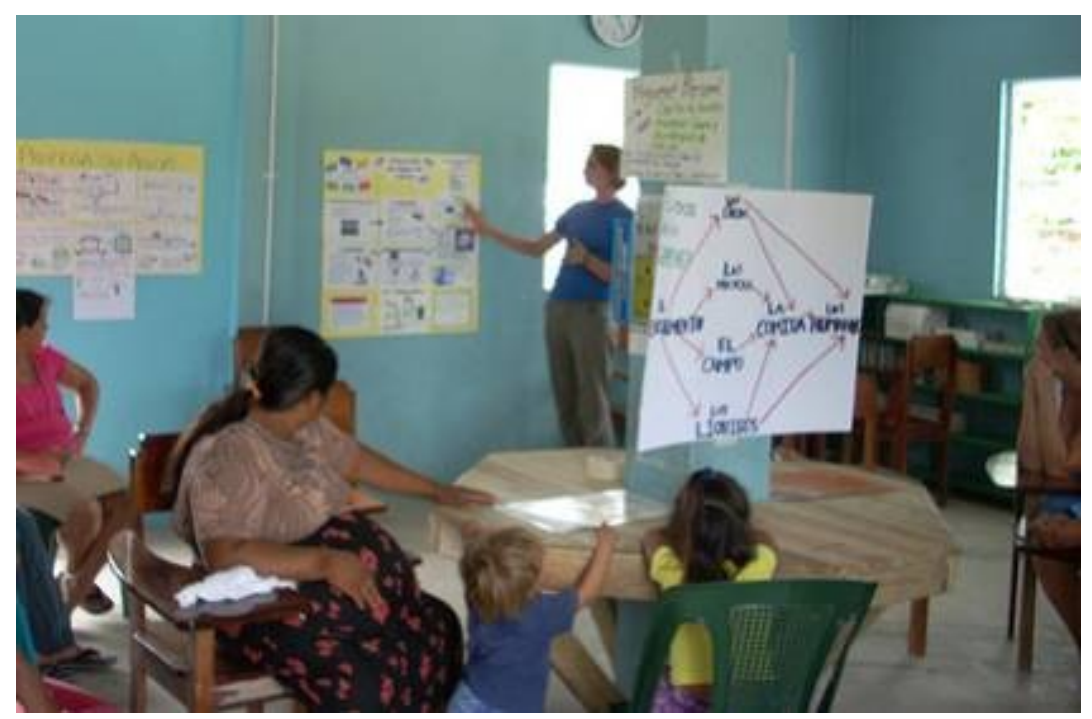

FIGURE 6

POSTER PRESENTATIONS AT THE COMMUNITY HEALTH FAIR COMMUNICATED OUR FINDINGS AND GAINED KNOWLEDGE TO THE COMMUNITY

Along with the poster presentations, we presented a tour and explanation of the school collection and treatment system so that those interested could see what we had been building and could see the actual materials and processes that they could use in the building of their own systems. Although we had originally planned to build the school's drinking water system in a series of open workshops, it quickly became apparent that this was an unreasonable plan for several reasons: we needed to build throughout the week due to our time constraints, when people would often be unavailable for a workshop; there were continuous unexpected setbacks that would have upset a consistent flow of workshops; and designing the construction process as an efficient series of workshops would take a great deal of prior preparation and planning. Through the formal presentation and tour of the school system as we built it, and then questions and answers, we explained how the system worked, how it had been built, difficulties we encountered, and draw backs to the system design as it pertained to household use.

To ensure the principal thoroughly understood the operation and maintenance (O\&M) of the school treatment system we described, both orally and later in a written manual, how the system worked in different conditions and the various O\&M tasks that needed to be completed. On a tour of the system, we explained the daily maintenance, cleaning procedures, how and when to use the filter bypass, and pump operation and addressed all of his questions. The principal already knew where we had obtained all of the materials in the case that he needed to make changes to the system, and we left the tools we had purchased at the school so that he or others could use them if needed. Additionally, we made plans to mail him a durable operations and maintenance manual that one of our team members was already working to create. Furthermore, the principal agreed to distribute pamphlets on contamination control and household water purification options that we would create for his students and their families. These pamphlets would be created in English and Spanish and would build on the poster presentations by adding more information and an annotated list of resources for people to learn more on their own.

To continue this engagement, some members of the project team are continuing the project through short return visits in the winter and spring of 2010 and one member of the project has 
formed a new project team that will return for several weeks in the summer. The winter trip will assess the current status of the treatment system, continue dialogue with the community, and introduce new students to the area. The spring trip will focus on renovating or replacing the biofilters so that they may again become a functioning part of the system, as well as strengthening relationships with local universities, and gauging the impact of our educational efforts. Currently, the summer project team is planning to hold instructional workshops on building point-of-use water filters for home use and renewing efforts to work with the Belize Department of Health to train local health workers. The goal for this long-term engagement is to empower residents of La Gracia with a sustainable means of purifying their own water using local resources.

\section{Conclusion}

The fundamental goals of our project were to create a sustainable solution to provide safe drinking water in La Gracia, and to gain and share knowledge through experience in communitybased engineering. Our methodology stressed local relevance and community participation in the solution design, which required gaining a thorough understanding of local resources and constraints before developing a detailed design plan. Once we achieved this understanding through interviews, a community message board, and surveys of materials, we developed the treatment design plan and continued to revise it from in-country. Our existing relationship and the trust we had built with the community over the past year and a half increased our capacity to create a design that was relevant to their needs. However, through this effort we realized the need for a balance of technical knowledge from academia with this gained understanding of real world constraints. We met with failures on some of the technical aspects of the filter design, but overall as a piece of a longer term engagement the project was still a success. We were able to raise awareness of the important link between health and water treatment and water source protection, share the knowledge that we developed on these issues, and furthermore construct an improved rainwater collection system to provide for the drinking water needs of the village school.

Within service learning projects, students aim high in their proposals and expectations, but the realistic goal is to avoid any harm to the community while aiming to maximize potential benefits through a process of engagement that enriches the students' education. In this project, rigorous education and advising in research ethics and protocols of international work led to an awareness, and thereby a minimization, of risk. Therefore, while certain technical elements of our design were unsuccessful, the overall project still did not introduce unmanageable risk or cause harm. Expanded education in technologies for small-scale infrastructure and more engaged technical advising in undergraduate service-learning projects would be a step towards creating the potential for even more productive projects. In conclusion, the students and their advisors should have an appreciation for both technological success and locally relevant design and make it their goal to achieve a successful balance between the two in their methodology and implementation. 


\section{ACKNowledgment}

The team deeply appreciated the partnership and assistance of La Gracia government school principal B. Watson, the many community members who volunteered their time and ideas, and our local student partner J. Ramos who was invaluable to our engagement with the community. Further support came from the faculty of Galen University, Belize Ministry of Health, the Social Investment Fund, and the National Association of Village Councils. The Jefferson Public Citizen program and the Center for Global Health provided funding for the project. The student team is grateful for the guidance of faculty advisors: R. Swap, J. Smith, T. Culver, and the many graduate students and Engineering Students Without Borders members who shared their experiences and expertise. Finally, we thank the anonymous reviewers for their valuable input.

\section{REFERENCES}

i “The Millennium Development Goals Report,” United Nations Department of Economic and Social Affairs, 2008. ${ }^{i i}$ B. Amadei and W. Wallace, "Engineering for Humanitarian Development: A Socio-Technical Approach" IEEE Technology and Society Magazine, 28, no. 4 (2009): 11.

iii Statistical Institute of Belize. "Background Information," National Association of Village Councils, http://navco.org.bz/background.html (accessed December 29, 2009)

iv Water \& Waste Utilities of the World $6^{\text {th }}$ ed., ABS Energy Research (London, 2004), 328.

v "Water Supply" in Field Guide to Appropriate Technology, ed. B. Hazeltine and C. Bull, 746 (Academic Press, 2003)

${ }^{\text {vi } B e l i z e}$ National Meteorological Services, “The Climate of Belize,” Belize National Meterological Services http://www.hydromet.gov.bz/Climate_Summary.htm (accessed May 10, 2009)

${ }^{\text {vii }}$ L. Huisman and W.E. Wood, "Theory of Biological Filtration" in Slow Sand Filtration (World Health Organization, 1974), 27-46.

viii "Water storage, treatment and distribution" in Engineering in Emergencies: A Practical Guide for Fieldworkers, $2^{\text {nd }} e d$., ed. J. Davis and R. Lambert, 334 (Practical Action, 2002)

ix L. Huismans and W.E. Wood, "Operation and Maintenance," 80. 